International Journal of Instruction e-ISSN: 1308-1470 • www.e-iji.net

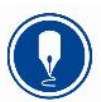

October $2018 \bullet$ Vol.11, No.4

p-ISSN: 1694-609X

$$
\text { pp. } 425-444
$$

Received: 22/05/2018

Revision: $13 / 06 / 2018$

Accepted: 17/06/2018

\title{
Construction and Validation of Foreign Language Learners' Dropout Questionnaire
}

\section{Ghasem Modarresi}

Asst. Prof., Corresponding author, Department of English, Quchan Branch, Islamic Azad University, Quchan, Iran, qasem.modarresi@gmail.com

\section{Elham Javan}

M.A., Department of English, Quchan Branch, Islamic Azad University, Quchan, Iran, javan.elh94@gmail.com

There exit cross-cultural differences in English classes regarding the factors that demotivate students and lead to dropout. The present study, following the guidelines suggested by Rowsell (1992), mainly aimed to design and validate a questionnaire for the reasons for dropout. To do so, the researchers, first, interviewed with 20 translation teachers and experts based on criterion sampling and the results emerged from the interviews were categorized into 16 common themes. Then, the questionnaire items including 28 items were constructed based on the commonalities emerged from the responses, and it was administered to 90 subjects during the two phases of pilot study. The researchers opted for factor analysis to determine the hidden traits of the questionnaire. Initially, PCA extracted 9 factors with eigenvalues greater than 1.0, accounting for $78 \%$ of the variance. Out of 28 items, 26 items had loadings of 0.40 or greater on any factor. During the second phase of the pilot study, the questionnaire was administered again to 90 subjects, and this time, PCA extracted 8 factors, accounting for $75 \%$ of the variance. Finally, the researchers explored the student's justifications for the major reasons for dropout from English institutes. The study offers practical implications for language teachers and students.

Keywords: demotivation, dropout, SEM, teaching methodologies, language learning

\section{INTRODUCTION}

Professionals in second language acquisition have recently become more interested in the causes of dropping out of in state schools, colleges, and private institutes (Roderick, 1993; Battin-Pearson \& Newcomb, 2000; Fortin, Lessard, \& Marcotte, 2010). Although there has been fairly limited literature on English learners' dropout, past literature has shown that dropping out of schools cannot be explained by one singular factor (Dorn, 1996; Battin-Pearson \& Newcomb, 2000; Millet \& Thin, 2005). Since lots of factors

Citation: Modarresi, G., \& Javan, E. (2018). Construction and Validation of Foreign Language Learners' Dropout Questionnaire. International Journal of Instruction, 11(4), 425-444. https://doi.org/10.12973/iji.2018.11427a 
such as learners' problems (including personal and family ones), educational issues, teachers' perspectives and demotivate factors can affect English learners' drop out, investigating such factors can shed light on students' progress. Among these factors, demotivation is regarded as an important one and scanty research has been carried out in this regard.

Previous studies emphasized the factors that demotivate students in learning a foreign language (Bloom \& Haskins, 2010). Bloom and Haskins (2010) mentioned that high school dropping out has serious results not only for people but also for community. Between 3.5 million and 6 million young Americans between the ages of 16 and 24 are dropouts of school according to expert estimates. For them, decreasing the number of young people who fail to stop high school and helping those who drop out return must be main goal for their population. Meshkata and Hassani (2012) clarified and categorized demotivating factors in learning English among Iranian high school students from severe to moderate sources of demotivation. The research results suggested that Iranian English learners considered lack of equipped classes for teaching English at schools, overemphasis on grammar, long passages, and expectancy to use grammatically correct English in the classroom as strong sources of demotivation which, in turn, result in quitting school. The next less severe demotivating factors were educational contents and materials. Teachers' competence and teaching styles were considered as moderate sources of demotivation.

Conducting studies and research into the reasons for dropout, especially in Iran, is of great importance based on which language policy, administrators, parents, teachers and researchers can delve into and reflect on the internal and external causes of discouragement. As Meshkata and Hassani (2012) claimed, in Iran, there is no adequate research dealing with factors which make students demotivated and lead them to quit school. They state such a demotivation has direct educational implications and due to day after day increasing importance of learning a foreign language, carrying out research in terms of related demotivating factors, leading to school dropout, seems indispensable. The study mainly seeks to identify dropout factors from teachers and experts' perspectives. As mentioned by McCroskey and Richmond (1990), dropout is an important theme in second language acquisition that has been underrated by professionals in ELT since the relationship between negative factors such as demotivation and frustration with the desire and willingness of students to participate in second language learning process has been ignored by the researchers in ELT field of study (Roderick, 1993).

Up to now, to the best knowledge of the researchers, nobody in the field of English language teaching and learning has designed and developed a questionnaire for the reasons for dropout, specifically in the context of our country. Indeed, since second language acquisition at higher levels is really critical and demanding for the learners, undertaking research in terms of related issues including dropout would be, obviously, fruitful. English learners constitute a large number of EFL learners in Iran. Consequently, their dropping out is considered as a kind of failure for schools. Thus, these schools ought to reconsider their policies so that they are able to seek the problems 
of dropping out. English schools are responsible for providing a proper learning environment for English learners and as a result should be aware of the reasons why they quit such schools.

In Iran, learning English mostly occurs in private English language schools rather than state schools. Foreign language learners constitute a large population of EFL learners in Iran. Therefore, since English schools are responsible for providing an appropriate communicative environment for the learners, abandoning English schools for any reason can be regarded as another failure. However, scanty research has been conducted on the experiences of English language learners in Iranian private English schools. Thus, this study attempts to pinpoint and explain various causes of foreign language learners' dropout from English institutes. Through analyzing English teachers' perspectives, the current study tries to find out the main factors of foreign language learners dropout.

The present study contributes to the field of English language teaching and learning mainly by constructing and validating a measurement tool for identifying and measuring the amount of dropout in the context of Iran. As an initial step, the study delves into the mind of foreign language learners by means of interview and questionnaire and investigates if foreign language learners who leave their studies are really still willing to pursue their studies and some external, uncontrollable factors impede their progress or not.

\section{LITERATURE REVIEW}

\section{Dropout in Foreign Language Setting}

Previous research on dropout indicated that learning English is unique in each context, and although there are commonalities, factors leading to dropout are different across cultures and societies (Jimerson, Anderson \& Whipple, 2002). That is why many researches have purposed to understand the school dropout concept better over the past two decades (Dunn, Chambers, \& Rabren, 2004). For example, in her qualitative study, Mackie's (2001) focused on the complex interplay of forces including personal, institutional, contextual and external forces which led up to the decision by a student to leave or to stay. According to Astone and McLanahan (1991), it is clear that the number of children enrolled in school has increased over time. Nevertheless, a significant proportion of children who start primary school are not completing this cycle. There are many factors associated with drop out, some of which belong to the individual, such as poor health or malnutrition and motivation. Others emerge from children's household situations such as child labor and poverty (Meyers, Pignault, \& Houseman, 2013). School level factors also play a role in increasing pressures to drop out such as teacher's absenteeism, school location and poor quality educational provision. According to Meyers (2011), the system of educational provision at the community level generates conditions that can ultimately impact on the likelihood of children to drop out from school. Therefore, both demand and supply driven factors, are embedded in cultural and contextual realities, which make each circumstance different. Nevertheless, it is possible to make general points about the causes of drop out (Vallerand, Fortier, \& Guay, 1997).

Hunt (2008) pointed out that there is not one single cause of drop out. Drop out is often 
a process rather than the result of one single event, and therefore has more than one proximate cause. In (1980), Gilmore and Smith stated that poverty appears to influence the demand for schooling, not only because it affects the inability of households to pay school fees and other costs associated with education, but also because it is associated with a high opportunity cost of schooling for children. As children grow older, the opportunity cost of education is even larger, hence increasing the pressure for children to work and earn income for the household as opposed to spending time in education (Hampden-Thompson, Warkentien, \& Daniel, 2009). Distance to schools, poor quality of education, inadequate facilities, overcrowded classrooms, inappropriate language of instruction, teacher absenteeism and, in the case of girls' school safety, are common causes for school dropout (Colclough, Rose, \& Tembon, 2000). These are seen as supply side causes of drop out, mainly driven at the school level.

There are often precursors to dropping out, where children could be seen to be at risk or vulnerable to early withdrawal (Hunt, 2008; Lewin, 2008; Ampiah \&Adu-Yeboah, 2009). These include grade repetition, low achievement, over age enrollers and children who have regular absences or previous temporary withdrawals from school. It is unclear whether grade repetition increases the chances of completion, but what is apparent is that grade repetition extends the age range in a particular grade, and thus increases the possibility of drop out. Teaching to different age groups has different requirements in terms of teaching/learning practices and curriculum (Little, 2008). Yet, in some countries age ranges in a Grade 1 class might range from 4 to 11 years and in Grade 6 from 10 to 21 years (Lewin, 2007). Children who are over age, due to late enrolment or high grade repetition, limit the number of years' children have in school as older children have greater pressures to earn income for the household (EPDC, 2009).

Uysal (2008) has done an extensive review on drop out factors. He believes that low social class and poverty, low educational level of the family, the environment within which the family lives, the quality of the school institution, problematic relations with the teachers, the schools giving low carrier education like vocational education, the supporting behavior of the school, school's size, alienation of the student from the school, the level of extracurricular activities in the school, negative atmosphere in the school, belongingness level of the student to the school, being casted out from the circle of friends, difficulty in establishing friendships and negative peer influences were stated to be the factors affecting the school dropout. Uysal (2008) also makes a differentiation between structural and individual factors. The structural factors are synonymous to the external factors and the individual factors stands for the internal ones within the learners in the present study.

The researchers of the present study believe that the previous experiments on the reasons for dropout were rather robust; however, there are other important reasons that can be diagnosed so as to help students prevent dropout and sustain their studies, what was called "dropout prevention programs" by Dupper (1993), but it has been underrated by researchers. Moreover, what previous literature lack is the attention to the factors that help students improve their language proficiency and autonomy so that they could 
pursue their studies on their own even if they are not satisfied with the educational settings.

\section{Theoretical Framework of the Study}

The current study follows the theoretical framework developed by Rowsell (1992) who outlined two main types of drop-out factors: the first results from external factors such as "illness", "relocation", or "employment", which can make it impossible for students to attend English classes. The second is related to internal factors such as learners' cognitive and affective domains. A case in the point for cognitive factors is when the learners find the process of learning a language harder and more complicated than they expected before joining the classes. On the other hand, when they cannot find proper rapport with their teacher, it can be taken as the affective factor. Based on Rowsell's (1992) dichotomy of external and internal factors of drop out, the researchers was inspired to design a drop out questionnaire.

\section{PURPOSE OF THE STUDY}

The present study mainly aimed to identify the main factors of foreign language learners' dropout and then, develop and validate a questionnaire of foreign language learners' dropout. The present study was an attempt to find the answer to each of the following questions:

1. What are the major reasons for dropout from the perspectives of teachers and experts?

2. Does a questionnaire of foreign language learners' dropout enjoy reliability and validity?

3. How do the students justify the major reasons for dropout from English institutes?

\section{METHOD}

The study followed both quantitative and qualitative research methods to carry out the study; however, the study mainly followed sophisticated statistics.

\section{Participants}

Initially, a pool of 20 English teachers teaching English language at private English institutes participated in the interview phase of the study. A criterion-based selection method, rather than a random one, was chosen as the sampling method. In this method, the researchers specified the criteria essential to the purposes of the study, and sought out participants fulfilling those specific attributes (Le Compete \& Preissle, 1993). The criteria set in this phase were: a) Being an English teacher, b) Being an BA, or MA in English Language Teaching, and c) Having experience of teaching for at least three years teaching English language to adult learners. They included both male and female students who voluntarily involved in the face-to-face interview held by the researchers. Moreover, five experts were who had $\mathrm{PhD}$ in English Language Teaching and had been teaching English at University level also participated in the study.

Furthermore, a pool of 90 students from English private institutes at Quchan and Mashhad (including Sama English Institute, Hafez English Institute, Kish English 
Institute, Safir English Institute, Hekmat English Institute, Shokooh English Institute) participated in this study. The students were selected based on availability sampling and they were students who had years of interval in their studies or who have left the institutes and were asked by phone with the help of the institute administrators to come and take part in the interview and filling out the questionnaire on the pre-specified date by prior agreement with the institute administers. They were asked to fill in the questionnaire and participate in the test of language proficiency. The sample also included those who came back to pursue their studies after years of dropout or those who decided not to continue their studies especially at the upper levels. The researchers just included those students who had already participated in the English courses for at least five terms. Finally, five students were interviewed regarding their justifications and reasons for the influence of dropout reasons on their success or failure in learning English based on availability sampling.

\section{Instrumentations}

The first instrument used in this study was a pool of two major interview questions which was compiled on two broad topic areas of internal factors and external factors for dropout reasons, and sent to the supervisor of the research for further scrutiny. The final version of the questions was used for the interviews with the teachers and the experts. The second instrument used in this study was foreign language learners' dropout questionnaire. Since nobody had already constructed the questionnaire, the researchers, first, developed and validated the questionnaire, named Foreign Language Learners' Dropout (FLLD) (Appendix A). The questionnaire can be used as an instrument for conducting research in the field of English language teaching and learning.

The third instrument used by the researchers was a semi-structured interview questionnaire, asking the students regarding the influence of dropout factors and their awareness and knowledge about the issue as well as how they can change such situations. Piloting of the interview schedule then took place with four non-participating individuals who were asked to comment on the interview design and their experience-asinterviewee. Two experts in the field of translation who had been teaching English language at university level checked the content validity of the questions. The researchers, having received the feedback from the experts, revised the questions in terms of their validity.

\section{Procedure}

First, Data collection obtained from the teachers took place over a series of three weeks. Each of the interviews varied considerably in length because for each participant probing questions eliciting follow-up and elaboration were asked until the researchers was sure that he had profoundly understood their responses to the topic areas in which data was being collected and until their answers became repetitive to the point of reaching saturation. Put otherwise; by creating appropriate space for the participants to express themselves freely, each interview quickly reached a point when the researchers was "empirically confident" (Dörnyei, 2007) that he had the data necessary to meaningfully answer the research questions. 
Following this, the current study adopted a straightforward procedure including three steps to ensure the reliability and validity of the scale as much as possible. First, the researchers designed the question items with reference to the data emerged from the qualitative study and previous literature on the topic. As the initial piloting, they asked two specialists in testing and assessment to indicate the problems of the items. Having received the feedback from the initial pilot group, the researchers carried out the final piloting during which the scale was administered to 90 students. The questions were written in English language. They included one section devoted to demographic information. The typed scale containing questions on a single page in a Likert type scale was used with 'strongly agree' at one end and 'strongly disagree' at the other. The minimum and maximum scores were 1 and 5 , respectively.

During the next step of the study, to gather the students' responses to the interview regarding the reasons for dropout factors, the questions were written in Persian Language and the students were required to reply to the questions in Persian Language since using their native language, they could express themselves more easily and precisely. Their writings were, then, translated into English, analyzed, and categorized. Using a simple writing task for data collection is most likely the best way to get the students express their thoughts about the issue mentioned above. The writing task resembled a semi-structured interview, in which subjects could express their thinking with very little interference. The pupils received the instructions both orally and in writing. The pupils had approximately twenty minutes to write down their answers.

\section{FINDINGS}

The researchers analyzed the research questions based on the statistical procedures including descriptive statistics and inferential statistics. The findings of the study are represented in three major steps:

\section{Interviews with the Teachers}

As for the first research question of the study regarding the major reasons for dropout from the perspectives of teachers and experts, having analyzed the results obtained from 20 English teachers who had at least three years of experience, the researchers using constant comparison analysis, tried to find out the most salient commonalities, categorizing and tabulating them as for the internal factors and external factors. The common factors which the teachers attribute to the adult L2 learners' dropouts of English classes were categorized into 16 factors as illustrated by Table 1 . The teachers responded to the questions in English, and the researchers listed the common factors in English language as displayed in Table 1. The most commonly cited factors included inability to use English (11.3\%), less effort (10.6\%), interest (9.9\%), teacher knowledge $(9.3 \%)$, financial problems $(9.3 \%)$, and higher age $(7.9 \%)$. Values, dissatisfaction, and administrative were the least commonly mentioned factors. 
Table 1

Dropout factors emerged from the interviews

\begin{tabular}{lcccc}
\hline Valid & Frequency & Percent & Valid Percent & Cumulative Percent \\
\hline inability to use English & 17 & 11.3 & 11.3 & 11.3 \\
less effort & 16 & 10.6 & 10.6 & 21.9 \\
interest & 15 & 9.9 & 9.9 & 31.8 \\
teacher knowledge & 14 & 9.3 & 9.3 & 41.1 \\
financial problems & 14 & 9.3 & 9.3 & 50.3 \\
higher age & 12 & 7.9 & 7.9 & 58.3 \\
less intelligence & 12 & 7.9 & 7.9 & 66.2 \\
base of communication & 11 & 7.3 & 7.3 & 73.5 \\
lack of proficient teachers & 9 & 6.0 & 6.0 & 79.5 \\
memorization & 8 & 5.3 & 5.3 & 84.8 \\
classroom situation & 7 & 4.6 & 4.6 & 89.4 \\
commutation difficulty & 6 & 4.0 & 4.0 & 93.4 \\
personnel behavior & 4 & 2.6 & 2.6 & 96.0 \\
values & 3 & 2.0 & 2.0 & 98.0 \\
dissatisfaction & 2 & 1.3 & 1.3 & .7 \\
administrative decisions & 1 & .7 & 100.0 & \\
Total & 151 & 100.0 & & \\
\hline
\end{tabular}

\section{Reliability and Construct Validity of FLLD}

As for the second research question of the study regarding the reliability and validity for the questionnaire of the FLLD, the researchers tried to find out what has actually shaped these types of dropout. The results of content analysis of interviews with English teachers and previous literature were a set of themes itemized in a questionnaire. Then, a 5-point likert- scale questionnaire, ranging from "strongly disagree" to "strongly agree", was developed. Each item in the questionnaire was designed to measure an aspect of the components of FLLD. Initially, it was important to calculate the reliability of all factors (6 factors) separately before running FA. To this end, Cronbach's Alpha was used, and the results are shown in Table 2 below. As seen, almost all factors enjoy an acceptable reliability index. This shows that FA can be implemented.

Table 2

Reliability of FLLD

\begin{tabular}{lll}
\hline Factors & N of items & Reliability Index \\
\hline Factor 1 & 5 & 0.74 \\
Factor 2 & 4 & 0.71 \\
Factor 3 & 3 & 0.70 \\
Factor 4 & 3 & 0.67 \\
Factor 5 & 4 & .72 \\
Factor 6 & 3 & .61 \\
The whole & 22 & 0.72 \\
\hline
\end{tabular}

Before running factor analysis, Bartlett's test of sphericity and the Kaiser-Meyer-Olkin measure was used to check for the adequacy of the sample size. The KMO measure was above $.60(\mathrm{KMO}=.641)$ and also the Bartlett's test of Sphericity was significant $(\mathrm{p}=.000<.05)$. After making sure about the factorability of data through KMO and 
Bartlett's test of Sphericity, factor analysis was run. For the exploratory factor analysis in this study, the extraction method of Principle Component Analysis and Varimax Rotation were adopted.

The designed questionnaire, consisted of 28 items, was administered to 90 subjects during the first phase of the pilot study. Initially, PCA extracted 9 factors with eigenvalues greater than 1.0 which accounted for $78 \%$ of the variance (see Table 3). 26 items had loadings of 0.40 or greater on any factor. Put it another way, item 24 was not found to have loadings of 0.40 or higher on any factor. Moreover, items 27 had the problem of multicollinearity or high loadings $(r>0.90)$. Therefore, they were removed from the questionnaire.

Table 3

Factors extracted from PCA (Phase I)

\begin{tabular}{|c|c|c|c|c|c|c|}
\hline \multirow[b]{2}{*}{ Component } & \multicolumn{3}{|c|}{ Initial Eigenvalues } & \multicolumn{3}{|c|}{ Extraction Sums of Squared Loadings } \\
\hline & Total & $\%$ of Variance & Cumulative $\%$ & Total & $\%$ of Variance & Cumulative $\%$ \\
\hline 1 & 6.573 & 23.474 & 23.474 & 6.573 & 23.474 & 23.474 \\
\hline 2 & 4.137 & 14.776 & 38.250 & 4.137 & 14.776 & 38.250 \\
\hline 3 & 2.387 & 8.525 & 46.775 & 2.387 & 8.525 & 46.775 \\
\hline 4 & 2.004 & 7.156 & 53.931 & 2.004 & 7.156 & 53.931 \\
\hline 5 & 1.792 & 6.400 & 60.331 & 1.792 & 6.400 & 60.331 \\
\hline 6 & 1.644 & 5.871 & 66.202 & 1.644 & 5.871 & 66.202 \\
\hline 7 & 1.314 & 4.694 & 70.896 & 1.314 & 4.694 & 70.896 \\
\hline 8 & 1.114 & 3.977 & 74.873 & 1.114 & 3.977 & 74.873 \\
\hline 9 & 1.036 & 3.699 & 78.573 & 1.036 & 3.699 & 78.573 \\
\hline 10 & .927 & 3.312 & 81.884 & & & \\
\hline 11 & .782 & 2.793 & 84.677 & & & \\
\hline 12 & .706 & 2.520 & 87.197 & & & \\
\hline 13 & .591 & 2.109 & 89.306 & & & \\
\hline 14 & .560 & 2.001 & 91.307 & & & \\
\hline 15 & .499 & 1.782 & 93.089 & & & \\
\hline 16 & .404 & 1.443 & 94.532 & & & \\
\hline 17 & .321 & 1.145 & 95.676 & & & \\
\hline 18 & .288 & 1.027 & 96.703 & & & \\
\hline 19 & .258 & .923 & 97.626 & & & \\
\hline 20 & .192 & .687 & 98.313 & & & \\
\hline 21 & .157 & .560 & 98.873 & & & \\
\hline 22 & .097 & .346 & 99.219 & & & \\
\hline 23 & .074 & .266 & 99.485 & & & \\
\hline 24 & .058 & .207 & 99.692 & & & \\
\hline 25 & .041 & .146 & 99.837 & & & \\
\hline 26 & .024 & .086 & 99.924 & & & \\
\hline 27 & .014 & .050 & 99.974 & & & \\
\hline 28 & .007 & .026 & 100.000 & & & \\
\hline
\end{tabular}

Extraction Method: Principal Component Analysis.

Then, the new questionnaire, consisted of 26 items, was administered again to 90 subjects in the second phase of the pilot study to reexamine the construct validity of the factor structure of the questionnaire through EFA. Again, items 18 and 24 were removed because their correlation coefficients were less than 0.40 . This time, PCA extracted 8 factors with eigenvalues greater than 1.0 which accounted for $75 \%$ of the variance. The researchers used the Scree Test to decide on the number of factors to retain for rotation. Given the natural bend or break point in the data where the curve flattens out, 
the results of the Scree Test illustrated that a six-factor solution might provide a more parsimonious grouping of the items. Then, oblique rotation was inspected. Varimax with Kaiser Normalization resulted in a rotated component matrix which appropriately represented the underlying factor structure as displayed in table 3 . With reference to this table, the first factor consisted of 6 items, the second factor consisted of 5 items, the third factor consisted of 3 items, the fourth factor consisted of 3 items, the fifth factor consisted of 4 items and the sixth factor consisted of 3 items. The whole items after factor rotation consisted of 24 items (see Table 4).

Table 4

Rotated component matrix for dropout factors

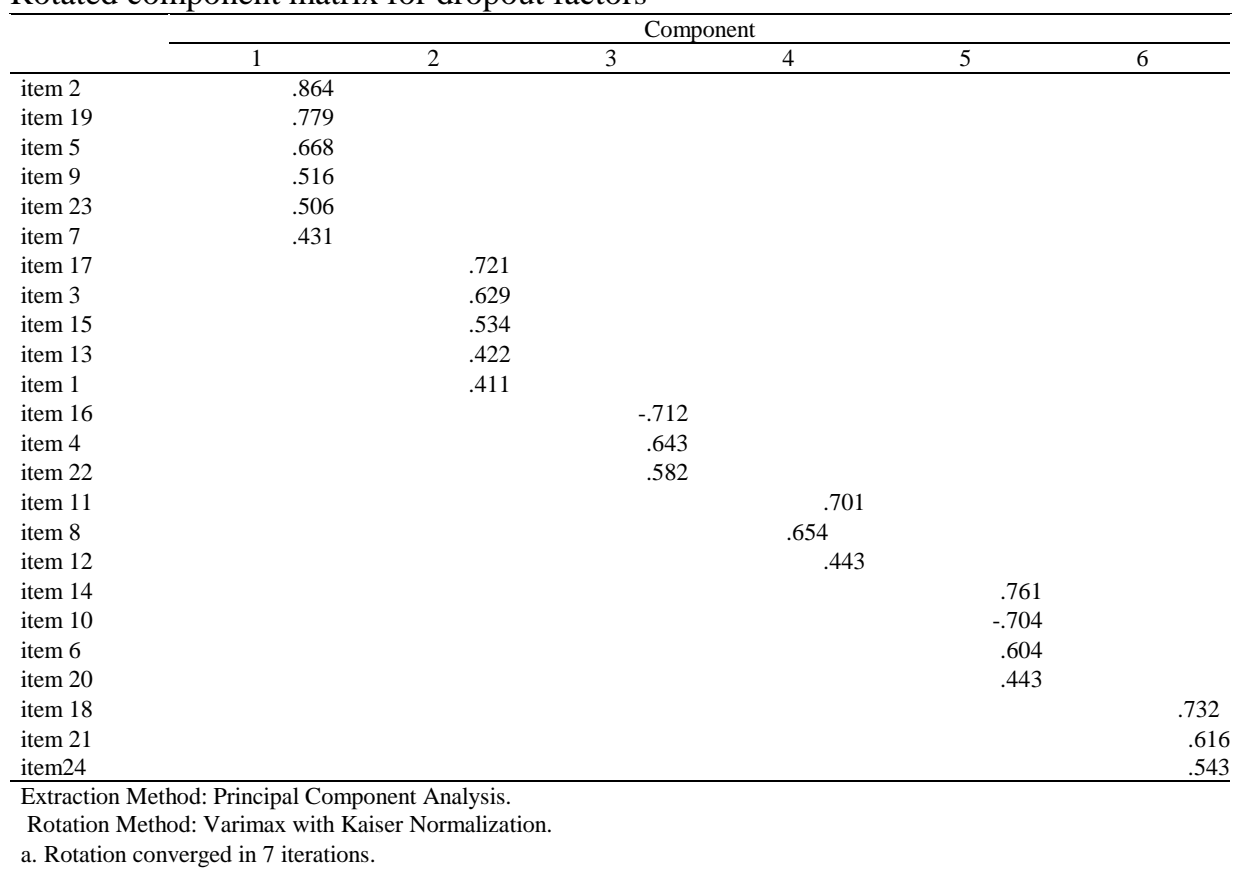

Following this, the results obtained from Amos 20 showed a good fit to the data. Because some measurement models did not show adequacy to the data, some modifications were made on the model (see Figure 1). These modifications included the removal of one item from factor one, and one item from factor two due to low loadings. The goodness-of-fit of the model improved substantially after modification. v2/df was 2.64, less than the cutoff point of 3; RMSEA was .07, less than .08; and GFI, CFI, and TLI were $.92, .91$, and .91 , respectively, all above the suggested cutoff point of .90 (Tseng \& Schmitt, 2008). 


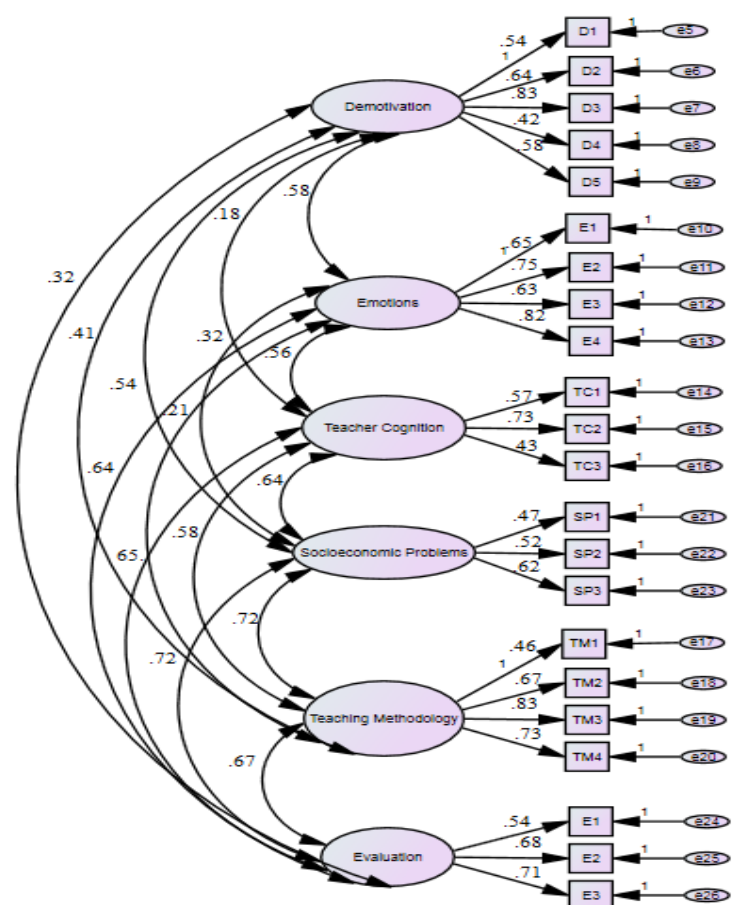

Figure 1

Measurement model of FLLD

Therefore, the final questionnaire consisted of six factors included 22 items. Taking the content of the items, these new factors were named: Factor one: Demotivation, Factor two: Emotions, Factor three: Teacher Cognition, and Factor four: Socioeconomic Problems, Factor Five: Teaching Methodology, and Factor Six: Administrative Decisions.

\section{Results Obtained from Interviews}

As for the last research question of the study regarding the student's justifications for the major reasons for dropout from English institutes, after transcription of the interviews, the researchers read them several times, highlighting and annotating major common themes. Initially, the researchers asked the participants to introduce themselves. Then, he asked the questions regarding the reasons for their dropouts. The main themes extracted from the interviews are reported below:

One of the students pinpointed the importance of psychological factors including lack of effort and self-confidence and also social factors including the marital status in learners' designation and frustration from English classes. She mainly stated:

"Lack of attempt and lack of self-confidence were the main reason for drop out. I our classmates and I actually quit English, because we afraid of such environment, 
we did not actually exerted enough effort and we had not enough self-confidence to interact in English freely. Moreover, due to the personal factors, due to the private matters outside the classroom and being busy in our life we cannot do well in our studies."

Another student believed that the main reason for his dropouts comes from his lack of motivation, need and especially his frustration due to his perceived failure in learning English, especially speaking skills. He mentioned:

"In the context of Iran, we, students, like to learn English, but we feel no need to learn speaking skills since we do not have to speak in English in the environment we live. Moreover, to me, learning English is hard especially at upper levels and I believe I am spending my time learning English, but I am unable to speak fluently and this leads to the negative feeling that I cannot learn English perfectly so that I designated and gave up the whole story".

Another student who had BA degree in Biology and participated in upper level classes for IELTS examination believed that students at upper levels are used to learning English for the test, that is, they study English to pass their exams such as IELTS or TOEFL examinations and having taken the test, they give up studying English and this is why, unfortunately, most of them cannot pass the test. She explained as follows:

"The problem with me at upper levels with that I enrolled to study IELTS at an institute, but the bitter fact was that my language proficiency did not match the class levels, not only me but also most of the other students in the class, perhaps because we had not been properly placed in such classes, or we had already passed several terms learning English, but we were not actually in the same level as we were studying. Thus, after a few term, I found out that I had passed several terms, but I am not successful in using English in speaking, writing or while listening I cannot understand, say, the film that I am watching, and this led to my decision to retreat from studying because, to me, such classes were not fruitful at all."

In sum, altogether, the results from the interviews showed that the students justify the reasons for their dropouts to both internal and external factors. Among the internal factors, students' frustration from repeated failure in using English in speaking and writing skills was more salient and among the external factors, imprecise evaluation of the students' current levels, and socio economic factors were more salient from the teachers' viewpoints.

\section{DISCUSSION}

The present study showed that different effective factors contribute to the students' dropout, and the main reasons entailed both internal factors such as demotivation because of repeated failure in using English or lack of emotional satisfaction and external factors such as financial problems or lack of proficient teachers at upper levels. Previous studies also showed that as time progressed, newer understandings of dropout extended beyond the wall of the home to encompass reasons outside the home, like in the community, at school, and within the student (Jimerson, Egeland, Sroufe, \& Carslon, 
2000). The results obtained from the study are in line with the previous study carried out by McCombs and Pope (1994) argued that the most important reason for giving up learning English is due to the students' low self-esteem. Moreover, the results of the study are in agreement with those of Horwitz, Horwits and Cope (1986) who pointed out that foreign language learning can cause a threat to self-esteem by depriving learners of their normal means of communication, their freedom to make errors, and their ability to behave like normal people.

As for the external factors, the present study revealed that teacher role and environment are important factors. Previous studies conducted by Williams, Burden, Poulet, and Maun (2004), showed that out of 957 reasons cited for students' dropouts, teacher role was among the six most commonly cited reasons. Dornyei (2005) remarked that despite the great number of individuals who spend a significant amount of time studying foreign languages worldwide, only relatively few will reach a level of L2 proficiency that satisfy them without any reservations. The unpleasant fact is that most learners fail in at least one L2 during their lifetime. Moreover, even successful learners frequently get into frustrating situations when they cannot use the L2 as well as they would hope to and because of this reason, they leave out their classes.

Cultural differences regarding the frequency and saliency of dropout reasons became also evident in this study. Indeed, the most frequent reasons for dropout may be dissimilar across different foreign language settings. For example, unlike Dorn (1996) who discovered that the most salient reason in the American context was retention which has long been considered the single strongest predictor of school dropout, the researchers found out that the main cause of dropout in the Iranian context was learners' inability to use English even after passing several courses.

Based on the findings, major conclusions can be drawn from the present study. Firstly, the line research on demotivating and dropout factors in the past two decades is not country-specific because similar pattern has been found in some other countries like Hungary and Japan (Dornyie, 2005). This confirms the fact that such research has external validity. Secondly, the findings highlight the fact that both internal and external factors are important in leaving out the English classroom at the upper levels in the context of Iran. Internal factors can be classified into two major constructs, including lack of time and lack of self-confidence, and external factors can be classified into two major constructs entailing school environment and teacher.

Although previous research on the issue shows that measuring dropout factors is hard in the domain of second language education, the present study illustrated that the work on the mental, social and cultural lives of the learners highlights the complexity of sociopsychological factors in second language acquisition. Point taken, there are some shared discourses among the individuals. The fact of the matter is that previous crosscultural investigations showed that among the vast number of reasons for de-motivation and dropouts, teacher and self-confidence predominate, and notably, in nearly all previous studies, environment of learning was among the few most common factors (see Tsi, 2000). The undeniable fact is that outcomes attributed to stable causes will be 
anticipated to be repeated in the future. Thus, if failure is taken as due to lack of intelligence, or any unfair teacher, failure will be repeated on future performance.

\section{CONCLUSION AND IMPLICATIONS}

The researchers concluded that both internal factors including demotivation and emotions and external factors including teacher, teaching methodology, administrative decisions and evaluation were the reasons for dropout. The point to be taken into account is that all of these variables have been documented to be influential in second language acquisition. The focus on both cognitive attributes such as effort, intelligence and emotional factors such as satisfaction and enjoyment are important in second language acquisition. Weiner (2000) believed that casual properties give information about the two detriments of motivation namely expectancy of success and value. The expectancy of success affects cognitive influences, while value influences affective reactions (Struthers, Weiner, and Allred, 1998). It is believed that we do things best if we believe we can succeed; otherwise, we give up the whole story.

Among the external factors contributing to the learners' dropouts, one of the most frequently-cited was school environment. For example, one of the students who has been rejoining English conversation at advanced levels believed "one of the most important factors to motivate the students is the environment because when we come to the institute, when we see some old stuffs, an old building, for example, we say that it's not good place". Indeed, there are students who judge the quality of an institute based on its physical location and properties and the first impression of the learners is important. Of course, occasionally, there have been learners who think that they are attracted to the beauty of an institute and its tempting propaganda, but in reality they are not provided with adequate facilities and effective teachers.

Like previous studies on the role of demotivating factors (Dornyie, 2005), teacher was regarded as one of the most determining factors in adult L2 learners' dropouts of English classes. Teachers are the most influential factor in any educational setting and teachers who were interviewed stated that an external factor for students' dropouts of English classes is the teacher. They believed that if the teachers have no motivation to teach assiduously, they transfer their lack of motivation to the students, especially students at higher levels because such students feel no need to take their time studying English language. According to Oxford \& Shearin (1994), the most important reason for students' demotivation is the teacher's personal relationship with the students such as teacher's showing lack of caring and general belligerence. Moreover, the teachers are constantly criticized by the students who give up their studies for being hypercritical and for favoring a student. The teachers also pointed out that their attitudes towards the course or material is a key factor and if they show no tendency and enthusiasm to the textbook or the material, they cannot manage the classroom effectively. A teacher can affect the students \& they can push them forward \& they can make them the best students \& vice versa. The results obtained from the interviews with the teachers revealed that not only teachers' attitudes and motivation are important but also teachers' knowledge and personality perform important roles. Indeed, the personality of the teachers has emotional impact on the learners' success and failure and there have been 
learners who attract to the English language courses because of their interest to the teachers.

During the interviews with the students those, who attributed their failure to external factors such as the teachers and teaching methodology, should recognize the fact that although external factors contribute to their success or failure, the role that internal factors play is more important because they have high control over these factors, and they can attribute their lack of success to their own lack of effort not to the teacher or lack of intelligence. One major benefit of interpretation of dropout is that it offers new avenues for adult L2 learners to resume their studies. There are learners who do not try hard because they think that if they are to be successful in learning English, they should have integrative motivation while the present study revealed that not only internal forces but also external forces orientate learners to success. The problem with teachers in teaching adult L2 learners is that they focus more on the cognitive aspect of learning maybe due to the atmosphere of the classrooms and the underlying assumptions of the teachers who mostly ignore the emotional factors in their classes. Learners need to be liked, valued, and appreciated. The classroom can be an environment where values and positive attitudes can be promoted. If a teacher can understand the importance of emotional factors, believing that all students can learn, he will offer opportunities for success to all students. To maintain their positive self-image and sustain their studies, students need not to be humiliated in the classrooms.

Students themselves should see how they can overcome their problems caused by negative emotions and how they can create and use more positive facilitative emotions to sustain their perseverance. As Goleman (1995) proposed the notion of 'emotional illiteracy' and he put forth a new vision for education as a solution, bringing together mind and heart in the classroom. For this, teachers should create a climate in the classrooms where mistakes can be made without embarrassment, where learning tasks lead to the feeling of success not failure. Moreover, students should know their current level and step in upper level classes if they can benefit from the teachers hints, prompts and mediation. The problem is that there are private institutes that place the learner in upper classes to remedy the shortage of students in their classes. Moreover, administrators should know that support from others and good feedback and external rewards all support students and adult L2 learners other supports help them promote in learning development.

\section{REFERENCES}

Ampiah, J. G., \& Adu-Yeboah, C. (2009). Mapping the incidence of school dropouts: A case study of communities in Northern Ghana. Comparative Education, 45 (2), 219-232.

Atone, N. M., \& McLanahan, S. S. (1991). Family structure, parental practices and high school completion. American Sociological Review, 56, $309-320$.

Battin-Pearson, S., \& Newcomb, M. D. (2000). Predictors of early high school dropout: A test of five theories. Journal of Educational Psychology, 92, 568-582. 
Bloom, D. \& Haskins, R. (2010). Helping high school dropouts improve their prospects. Journal of the Future of Children, 12, 1-8.

Colclough, C., Rose, P., \& Tembon, M. (2000). Gender inequalities in primary schooling: The roles of poverty and adverse cultural practice. International Journal of Educational Development, 20 (1), 5-27.

Dorn, S. (1996). Creating the dropout: An institutional and social history of school failure. Westport: Connecticut London.

Dörnyei, Z. (2005). The psychology of the language learner: Individual differences in second language acquisition. Mahwah, NJ: Lawrence Erlbaum.

Dörnyei, Z. (2007). Research methods in applied linguistics. Oxford: Oxford University Press.

Dunn, C., Chambers, D. \& Rabren, R. (2004). Variables affecting students' decisions to drop out. Remedial and Special Education, 25 (5), 314-323.

Dupper, D. R. (1993). Preventing school dropouts: Guidelines for school social work practice. Children \& Schools, 15 (3), 141-149.

Education Policy and Data Center (EPDC) (2009). Pupil performance and age: A study of promotion, repetition, and dropout rates among pupils in four age groups in 35 developing countries. Washington DC: Education Policy and Data Center.

Fortin, L., Lessard, A., \& Marcotte, D. (2010). Comparison by gender of students with behavior problems who dropped out of school. Procedia, Social and Behavioral Journal: Innovation and Creativity in Education, 2 (2), 5530-5538.

Gilmore, P., \& Smith, D. (1980). Contextualizing dropping out. In H. T. Trueba, G. Spindler, L. Spindler, H. Trueba, G. Spindler, \& L. Spindler (Eds.), What do anthropologists have to say about dropouts? (pp. 43-51). New York: Falmer.

Goleman, D. (1995). Emotional intelligence. New York: Bantam Books.

Hampden-Thompson, G., Warkentien, S., \& Daniel, B. (2009). Course credit accrual and dropping out of high school, by student characteristics. National Center for Educational Statistics. Jessup: U.S. Department of Education.

Horwitz, E. K., Horwitz, M. B., \& Cope, J. A. (1986). Foreign language classroom anxiety. Modern Language Journal, 70, 125-132.

Hunt, F. (2008). Dropping out from school: A cross country review of the literature. Brighton: University of Sussex.

Jimerson, S. R., Anderson, G. E. \& Whipple, A. D. (2002). Winning the battle and losing the war: Examining the relation between grade retention and dropping out of high school. Psychology in the Schools, 39 (4), 441-457. 
Jimerson, S., Egeland, B., Sroufe, L. A. \& Carslon, B. (2000). A Prospective longitudinal study of high school dropout: Examining multiple predictors acrossdevelopment. Journal of School Psychology, 28 (6), 525-549.

LeCompete, M. \& Preissle, J. (1993). Ethnography and qualitative design in education research. San Diego, CA: Academic Press.

Lewin, K. M. (2007). Improving access, equity and transitions in education: Creating a research agenda. Brighton: University of Sussex.

Lewin, K. M. (2008). Access, age and grade. Create Policy Brief, 2, 181-196.

Little, A. W. (2008). Size matters for EFA: Create pathways to access. Brighton: University of Sussex.

Mackie, S. A. (2001). Jumping the hurdles - Undergraduate student withdrawal behavior. Innovations in Education and Teaching International, 38 (3), 265-276.

McCombs, B. L., \& Pope, J. E. (1994). Motivating hard to reach students. Washington, DC: American Psychological Association.

McCroskey, J. C., \& Richmond, V. P. (1990). Willingness to communicate: A cognitive view. Journal of Social Behavior and Personality, 5, 19-37.

Meyers, R. (2011). Teachers' perception of school drop-out in Luxembourg. Procedia, Social and Behavioral Journal, 15, 1514-1517.

Meyers, R., Pignault, A., \& Houseman, C. (2013). The role of motivation and selfregulation in Dropping out of school. Procedia, Social and Behavioral Journal, 89, 270-275.

Meshkata, M. \& Hassani, M. (2012). Demotivating factors in learning English: The case of Iran. Procedia, Social and Behavioral Journal: World Conference on Learning, Teaching \& Administration, 31, 745-749.

Millet, M., \& Thin, D. (2005). Ruptures scalars: The question of drop out. Paris: Presses Universitaires de France.

Oxford, R., \& Shearin, J. (1994). Language learning motivation: Expanding the theoretical framework. The Modern Language Journal, 78 (1), 12-28.

Roderick, M. (1993). The path to dropping out: Evidence for intervention. London: Auburn House.

Rowsell, L. V. (1992). Adults dropping out? Try repgrid. ELT Journal, 46 (4), 362-372.

Struthers, C. W., Weiner, B., \& Allred, K. (1998). Effects of causal attributions on personal decisions: a social motivation perspective. Basic and Applied Social Psychology, 20 (2), 155-166.

Tseng, W. T., \& Schmitt, N. (2008). Toward a model of motivated vocabulary learning: A structural equation modeling approach. Language Learning, 58, 357-400. 
Tsi, L. (2000). Student perceptions for foreign language study: A qualitative analysis of foreign language autobiographies. The Modern Language Journal, 84, 69-84.

Uysal, A. (2008). Okulu bırakma sorunu üzerine tartışmalar: Çevresel faktörler. Milli Ĕgitim, 178, 139-150.

Vallerand, R. J., Fortier, M. S. \& Guay, F. (1997). Self-determination and persistence in a real-life setting: Toward a motivational model of high school dropout. Journal of Personality and Social Psychology, 72 (5), 1161-1176.

Weiner, B. (2000). Intrapersonal and interpersonal theories of motivation from an attributional perspective. Educational Psychologist Review, 12 (1), 1-14.

Williams, M., Burden, R., Poulet, G., \& Maun, I. (2004). Learner's perceptions of their successes and failures in foreign Language learning. Language Learning Journal, 30, 19-29. 


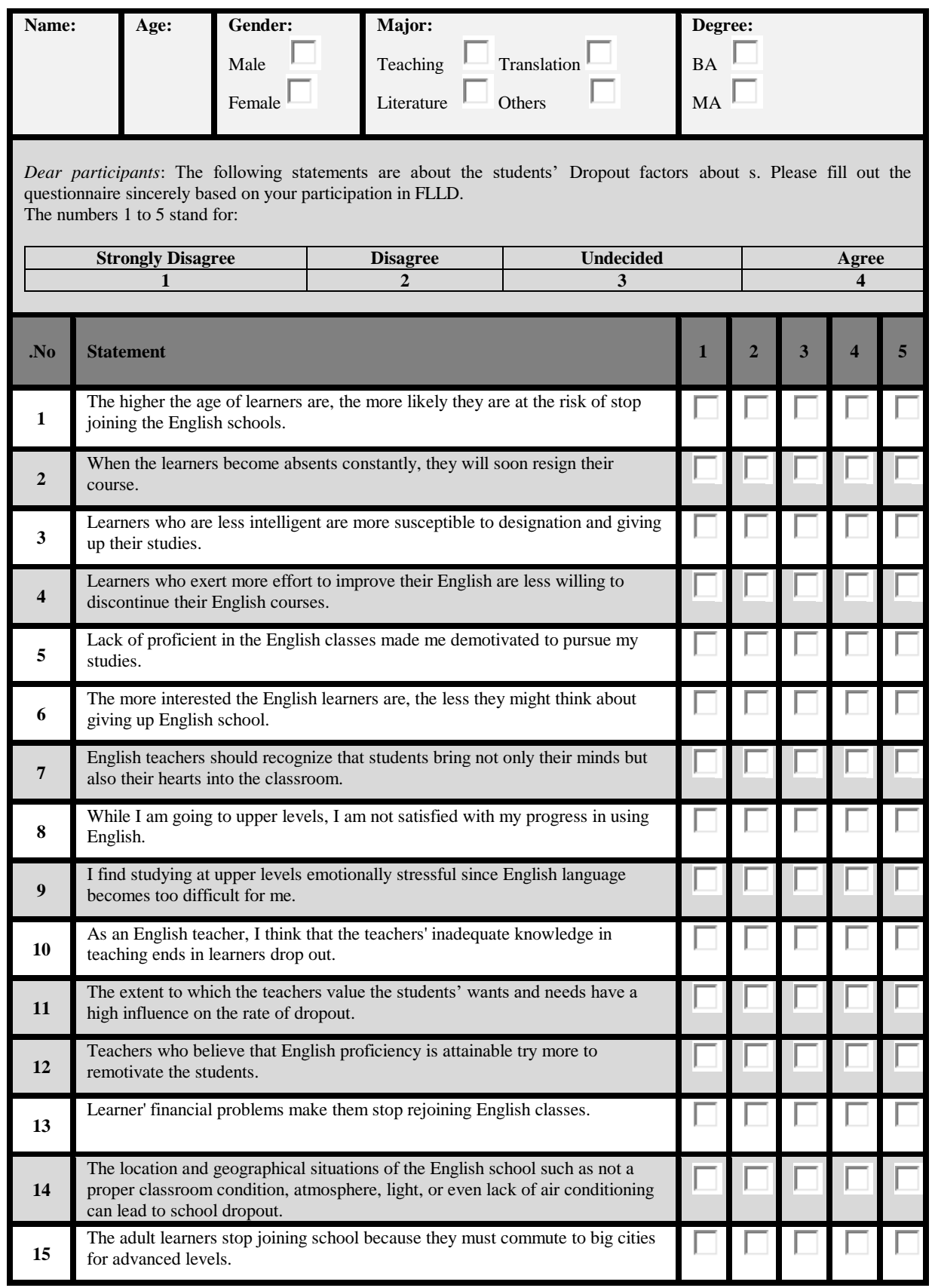

International Journal of Instruction, October $2018 \bullet$ Vol.11, No.4 


\begin{tabular}{|c|l|}
\hline 16 & $\begin{array}{l}\text { One reason for drop out is that the current instructions in the English schools } \\
\text { are not connected to the learners' needs. }\end{array}$ \\
\hline $\mathbf{1 7}$ & $\begin{array}{l}\text { That I was forced to memorize the sentences in the textbooks too often made } \\
\text { the course tedious for me. }\end{array}$ \\
\hline $\mathbf{1 8}$ & The teachers mostly used Persian language to present the courses to us. \\
\hline $\mathbf{2 0}$ & $\begin{array}{l}\text { Since I could not communicate in real situations in English language, I decided } \\
\text { to give up studying. } \\
\text { The way personnel such as receptionists behave and interact with the learners }\end{array}$ \\
$\mathbf{2 1}$ & $\begin{array}{l}\text { After studying English for several terms, I found that most of scores I received } \\
\text { rather easily from the teachers were not compatible with my present } \\
\text { knowledge. }\end{array}$ \\
\hline $\mathbf{2 2}$ & $\begin{array}{l}\text { The administrative decisions for placing me in the right level were based on } \\
\text { their own benefits rather than my own proficiency level. }\end{array}$
\end{tabular}

International Journal of Instruction, October $2018 \bullet$ Vol.11, No.4 